\title{
¿DÓNDE ESTÁ EL CONOCIMIENTO QUE SE PERDIÓ CON LA INFORMACIÓN?
}

\author{
AUTORES: ALCALDE PEREA, Ignacio Javier \\ Profesor Consultor - Universitat Oberta de Catalunya - España
}

ialcalde@uoc.edu

\begin{abstract}
Resumen
Tan solo hace falta analizar las palabras infografía o visualización de datos en Google Trends para darnos cuenta el protagonismo que están tomando. Aunque el concepto de infografía es bastante antiguo en si, hoy en día se ha vuelto popular y masivo. Se dice que la infografía consiste en "transformar la información en conocimiento”. Pero ¿Puede ser este
\end{abstract}

transferido realmente el conocimiento de una forma visual?, ¿Ofrecen las infografías actuales síntesis de conocimiento?, ¿Existe algún proceso para crear infografías que faciliten la transmisión de conocimiento?. Explorar una aproximación a estas preguntas es el objetivo de este paper.

\section{Infografia: ¿Dónde está el conocimiento que se perdió con la información?}

La visualización de la información, y es una disciplina realmente fascinante cuyo interés no ha hecho mas que despegar. Si por ejemplo ponemos el término "infographics" o "data visualization" en google trends, podremos comprobar que el interés crece día a día. Pero... ¿Qué es realmente la visualización de la información? La podríamos definir como la representación y presentación de datos e información que explota nuestra capacidad de percepción visual con el fin de ampliar el conocimiento. Una visualización de información, explica historias, simplifica, mide, compara, explora, descubre... con el objetivo de transformar los datos en información, la información en conocimiento, comunicando visualmente.

Dentro de la disciplina de la representación gráfica de la información encontramos la infografía , la cual podemos entender como un método para representar la información de forma icónica, gráfica y textual de manera que el usuario pueda compren- derla fácilmente, y empleando para ello generalmente herramientas digitales. Es un medio de acoplamiento de la comunicación que ayuda a enfocar las grandes ideas con los conceptos abstractos y complicados. En ellas podemos narrar historias, explicar acontecimientos, describir situaciones, exponer procesos, comparar, presentar información etc.

Como consultor docente de una universidad online, constato que la mayoría de mis alumnos no tienen el tiempo para el estudio concentrado. Una creciente mayoría prefieren mirar una infografía porque comunica una idea con la velocidad, ya que las palabras y los números por sí solos leídos en densas páginas de texto no facilitan la transmisión y síntesis del conocimiento. Queda claro que como recurso docente la infografía, si está realizada con criterio, es un recurso fabuloso cara a presentar información y facilitar la transmisión de conocimiento. 
Existen infinidad de infografías en la red que se utilizan de forma muy automática y con herramientas con plantillas y hechas con premura que tan solo exponen información de forma visual. Josep Maria Turuguet en su post llamado "INFORMACIÓN, CONOCIMIENTO, SABIDURÍA”, expone la pregunta ¿Dónde está el conocimiento que se perdió con la información?, me hizo pensar en la infografía como recurso para activar el conocimiento desde la información. ¿Existe algún proceso para generar un infografía que provoque ese conocimiento? ¿Puede ser este transferido realmente el conocimiento de una forma visual?

Algunos profesionales de la gestión del conocimiento indican que el conocimiento puede ser transferido, aunque en mi opinión el conocimiento es personal y a diferencia de la información, no se puede transferir.

Para ello debemos reflexionar sobre los dos tipos de conocimiento, el implícito y el explicito e ir más allá del error más común, pensar en el conocimiento como nada más que un repositorio de información y contenido.

El conocimiento explícito (decisiones, actos, procedimientos, etc.) es fácil de capturar, mediante los sistemas de gestión de documental. Además somos seres sociales que normalmente en nuestra vida personal nos comunicamos y compartimos experiencias en las que hemos aprendido. Como bien indica Javier Martínez en su charla TED "eres más inteligente que la empresa para la que trabajas" de TEDxUDP, aprender consiste en acumular experiencia reutilizable en el futuro, y depende de tres factores, motivación, tiempo y oportunidad de practicar. Una vez aprendido compartimos el nuevo conocimiento generado mediante las historias, que son las que que proporcionan el contexto adicional, la comprensión y el recuerdo del mismo.

Por otro lado el conocimiento implícito requiere interpretación de la información recogida y el compromiso personal de dar sentido a la misma. Cualquier organización puede recoger gran cantidad de datos e información, pero el conocimiento y extracción de de valor es personal, aunque pero puede ser aprendido. Es en este contexto pues donde la infografía juega un papel principal, ya que es una narrativa visual para "contar historias" y el comunicar mediante historias visuales facilita la comprensión.

Como indico en la entrevista que me realizó la UOC con motivo de la presentación de de mi libro Visualización de la información de los datos al conocimiento, el $80 \%$ de la infografías que circulan por la red, son más o menos atractivas visualmente pero no ofrecen valor ¿por qué? Pues principalmente porque no se trabaja correctamente todo el proceso de creación.

El siguiente esquema , inspirado en el explicado en sus charlas por infógrafo Jordi Català, podemos ver que el proceso de creación infográfico, lo que hacemos en si es pensar $>$ visualizar $>$ comunicar. De hecho gestionamos competencias de captura de datos, información, análisis e interpretación, síntesis, organización, visualización, y narrativa.

Tal es el reto que deberemos levantar en el siglo XXI: devolver a la alteridad y también al altruismo, - como parte integrante de la cultura del respeto de la mirada del otro-, todo el lugar central que deberían tener, apoyándonos en la fuerza transformadora como herramienta de la revolución tecnológica. Como lo ha expresado Milad Doueihi [6], se trata de reivindicar así un "humanismo digital", convencidos que el digital, puede ser llevado en una perspectiva de creación de nuevas formas de humanidades y urbanidades. Tenemos un espacio posible ante nosotros de creatividad para que las tecnologías conectadas, nos ayuden a anclar la empatía y el altruismo en un espacio social y territorio dados. Con la capacidad de conectarse sin interrupción, asistimos al desarrollo de esta hyperproximidad entre los ciudadanos, que nos muestra que las nuevas sociedades de compartir y de colaboración podrían ser posibles. Dejamos entonces el mundo de la utopía tecno céntrica y neo positivista, para que el imaginario y su hibridación en la realidad, le de paso en la acción a la alteridad y la empatía, aquí y ahora. 
Figura 1. Proceso de creación infográfico

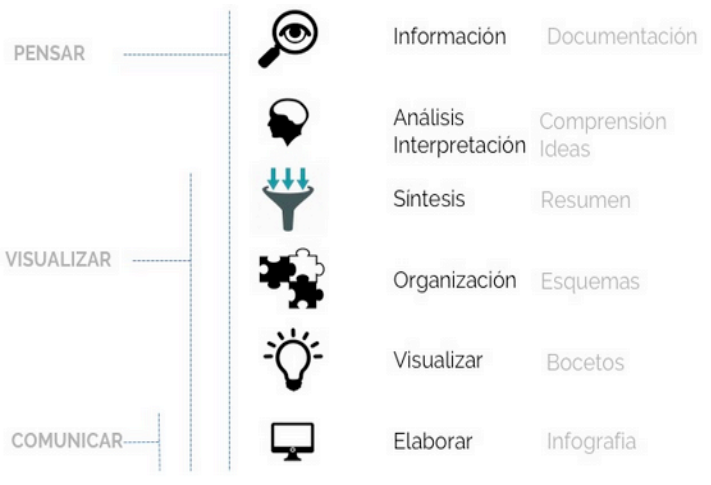

Fuente: Jordi Català
Es en este proceso dónde fijamos la comprensión de información, ya que trabajamos en diferentes planos, visual, narrativo, analítico, y es en la historia visual es dónde activamos el conocimiento. Como resumen el proceso crear de adquirir un conocimiento es personal y basado en la comprensión, pero el proceso infográfico que permita esa síntesis puede ser aprendido.

\section{Webgrafia}

- Josep Ma Turuguet: Información, conocimiento, sabiduría. INED 21. Recuperado de: http://ined21.com/informacionconocimiento-sabiduria/

- Javier Martínez. Eres Más Inteligente que la Empresa para la que Trabajas. Recuperado de: https://youtu.be/rNwnEwlsNSA
- Jordi Català. Infographics. Recuperado de: http://www.jordicatalainfographics.com/quie acuten-soy.html

\section{Forma de Citación}

ALCALDE PEREA, Ignacio Javier: ¿Dónde está el conocimiento que se perdió con la información?. Revista Communication Papers, $N^{\circ} 8$ (Monográfico II), páginas 54 a 56. Departamento de Filología y Comunicación de la Universidad de Girona. Recuperado el _ de___ de 2 de: http://www.communicationpapers.es 